\title{
EXPLORING SMART CITY RESEARCH FROM INFORMATION SYSTEMS AND MANAGEMENT PERSPECTIVES
}

\author{
Mario Jadrić ${ }^{1}$ \\ DOI: https://doi.org/10.31410/ITEMA.S.P.2020.1
}

\begin{abstract}
Research in the smart city domain is characterised by distinct multidisciplinarity. The reason for this is the broadness of the domain, classified into six key categories: smart governance, smart people, smart living, smart mobility, smart economy, and smart environment, all focal points of research in separate scientific fields. Also, many researchers argue about the best approach and steps in the development of smart cities highlighting different technological, economic, or sociological aspects of research. This paper aims to explore and clarify the differences in smart city research from two different perspectives information systems and management. Abstracts from almost 5.000 papers from the WoS database and more than 7.000 papers from the Scopus database were downloaded and analysed. Publications categorised into two perspectives were then analysed descriptively, including data about the number of papers, year of publication, and country of publishing. Furthermore, automated text mining procedure was performed for additional interpretation of attributes and occurrences from the two observed perspectives. The use of six smart city categories as keywords within each set was also analysed and visualised. The results indicate clear differences in both research approaches and research subjects between the two perspectives.
\end{abstract}

Keywords: Smart city, Information systems, Management, Text mining.

\section{INTRODUCTION}

$S^{t}$ mart cities are getting smarter due to the wide range of increasingly available digital technologies. For example, the cities are becoming equipped with various electronic devices for different applications and use, such as street cameras, transport system sensors, smart lighting, parking, and similar. There are also initiatives to provide value-added services within the applications, such as Google street view, global positioning systems, and more, where a large proportion of the population using mobile devices positively contributes to the development of smart cities (Rathore et al., 2016). The "smartness" of a city is a measure of convergence of different devices and systems into a unified framework for city-wide data management throughout their life cycle. Ultimately, the goal is to improve the quality of citizens' life, reduce the cost of living, and achieve a sustainable environment (Gharaibeh et al., 2017). For that reason, the development of smart services in different areas requires the incorporation of advanced technologies into urban activities in various areas (Kumar et al., 2018). According to Manville et al. (2014), a Smart City is a city that implements at least one initiative in one out of six key areas: Smart Governance, Smart People, Smart Living, Smart Mobility, Smart Economy, and Smart Environment.

While some researchers criticise first-generation smart cities for failing to engage citizens and meet their needs, many demand a shift beyond the narrow framework of meeting environmental 
and economic goals and opening up to social issues important for smart city development (Trencher, 2018). On that note, Mora et al. (2018) highlight a deep-rooted divergence in smart city research and divergent hypotheses about what principles should be considered when implementing smart city strategies.

To explore and bring light to stated differences in the smart city domain, this study is designed around and based on literature review and text mining. The following research questions were posited: (1) Is there a difference in terms of the geographical distribution of smart city studies?, (2) Is there a specific trend that can be recognised related to the time of publishing of the relevant papers?, (3) What has been the focus of recent studies in the field of smart cities?, (4) Is there a difference in smart city research from information systems and management perspectives?, (5) Is there a difference in occurrences of smart city key categories from information systems and management perspectives? The paper follows the standard structure: Section 2 contains a detailed explanation of the used methodology with the procedure of data retrieval and text mining technique. Section 3 presents the results, followed by Section 4 that includes the elaboration of the results based on the analysis of WoS top-cited papers in the field. Section 5 presents future research directions, and section 6 concludes the paper by providing a short overview of the overall contribution of the paper.

\section{METHODOLOGY}

With the repositories of scientific papers containing textual and complete data sources, together with the increase in the volume and diversity of these sources, conducting a systematic review of the literature has become increasingly complex (Jadric et al., 2020). For a researcher, a domain of interest can contain thousands of titles and abstracts. For that purpose, text mining as an approach can be used to optimise the process. This data mining technique where the input data is in the form of unstructured text has enabled an automated review of a large number of published papers. The technique has become essential in support of knowledge discovery in texts (Justicia De La Torre et al., 2018) and it is commonly used to extract useful hidden information and patterns in a text (Kaur \& Chopra, 2016). In this particular case, an insight into the occurrences of certain keywords related to the domain of a smart city was investigated from research perspectives of information systems and management. Standard phases of text mining - data retrieval, data extraction, and knowledge discovery were followed for that purpose.

\section{Data}

WoS and Scopus databases were chosen as a source for the analysis to analyse the diversity of perspectives in the domain of smart cities using text mining techniques. Although in this way the papers published in some other databases that distribute research studies from the smart city domain were excluded from the analysis, the focus on all journals at this stage of the analysis would introduce additional complexity. Also, this would affect the interpretability of the results as the impact of papers published in low-citation journals would be equal to those that are highly-cited. For text mining, abstracts of papers were downloaded, in line with previous studies (Daenekindt and Huisman 2020; Jadric et al., 2020) and because of the four criteria the abstracts meet: (1) availability for download from WoS and Scopus databases, (2) abstracts are available free of charge, (3) the abstracts represent a summary of the papers, and (4) the abstracts are similar in terms of scope and style in different journals. This approach reduces the impact of paper size on the representation of a particular topic in the results of the analysis. 
WoS Core Collection database was first searched for the topic "smart cit *" resulting in 12.889 records. The search was then narrowed to focus the research on the papers in which smart city is the primary topic of interest, using the following criteria: (TITLE: ("smart cit *") Refined by DOCUMENT TYPES: (PROCEEDINGS PAPER OR ARTICLE OR BOOK CHAPTER) AND LANGUAGES: (ENGLISH) Timespan: All years. Indexes: SCI-EXPANDED, SSCI, A \& HCI, CPCI-S, CPCI-SSH, BKCI-S, BKCI-SSH, ESCI, CCR-EXPANDED, IC.); this resulting in 4.994 records from Web of Science Core Collection. The search was further reduced to WEB OF SCIENCE CATEGORIES to collect abstracts of papers from the Information systems perspective: (COMPUTER SCIENCE INFORMATION SYSTEMS), resulting in 1.038 records marked as Computer Science Information Systems (100\%), Telecommunications (42.7\%), Engineering Electrical Electronic (35.5\%), Computer Science Theory Methods (28.9\%), Computer Science Artificial Intelligence (12.4\%), and Computer Science Hardware Architecture (12.1\%) and so on. The initial set of 4,994 papers was also reduced to contain abstracts from the Management perspective to 342 papers based on WEB OF SCIENCE CATEGORIES: (MANAGEMENT OR BUSINESS OR ECONOMICS). There were 158 papers marked with the category Management (46.2\%), Business (41.2\%), Economics (35.4), Regional Urban Planning (19.9\%), Urban Studies (10.5\%), Business Finance $(4.1 \%)$, and so on.

Similarly, the SCOPUS database was searched first for the topic "smart cit *" which resulted in 24.962 document results. The search was then reduced to focus on the papers in which smart city is the primary topic of interest using criteria TITLE ("Smart cit *") AND (LIMIT-TO) (DOCTYPE, "cp") OR LIMIT-TO (DOCTYPE, "ar ") OR LIMIT-TO (DOCTYPE," ch ")) AND (LIMIT-TO (LANGUAGE," English "))) resulting in 7.099 records. To collect abstracts of papers from the Information systems perspective in Scopus databases, given the different categorisation comparing to WoS, only a search by subject area "Computer science" was possible. From the initial set of 7.099 papers, the search was reduced to 4.631 document results based on the following query: TITLE ("Smart cit *") AND (LIMIT-TO) (DOCTYPE, "cp") OR LIMIT-TO (DOCTYPE, "ar") OR LIMIT-TO (DOCTYPE, "ch")) AND (LIMIT-TO (LANGUAGE, "English")) AND (LIMIT-TO (SUBJAREA, "COMP")). There were 100\% papers marked as Computer Science, Engineering (35.39\%), Mathematics (17.67\%), Social Sciences (15.12\%), Decision Sciences (11.33\%), and Energy (5.72). Further, to collect abstracts from the Management perspective, the search was reduced using criteria TITLE ("Smart cit *") AND (LIMIT-TO) (DOCTYPE, "cp") OR LIMIT-TO (DOCTYPE, "ar") OR LIMIT-TO DOCTYPE, ("ch")) AND (LIMIT-TO (LANGUAGE, "English")) AND (LIMITTO (SUBJAREA, "BUSI")). Business, Management, and Accounting subject area contain 650 records, $100 \%$ from Business, Management, and Accounting area, Social Sciences (37.56\%), Computer Science (32.21\%), Engineering (28.55\%), Decision Sciences (26.72\%), and Economics, Econometrics, and Finance (17.10\%).

\section{Procedure}

The tool used for conducting text mining was RapidMiner Studio, accessible as a stand-alone open-source application that provides a powerful platform for data mining. Text mining was done following the standard procedure (Figure 1) and using operators (RapidMiner, 2020): (1) Tokenize, (2) Extract information, (3) Filter Stopwords, (4) Stem (Porter), and (5) Transform Cases. Tokenize operator splits the text of a document into a sequence of tokens (Hrcka et al., 2017) which resulted in tokens consisting of one single word. Generated words from 2 documents (WoS and Scopus paper abstracts) were thus transferred to attributes through tokenisation. Extract information operator extracts information from the structured content of 
a document that might be added as an attribute in this process later. Filter Stopwords (English) filters English stopwords based on a built-in stopword list. Stopword mainly refers to conjunctions and papers that contribute to the readability of texts written in English but do not contribute to the analysis.

After this, words were stemmed using Porter's words stemming algorithm applying an iterative, rule-based replacement of word suffixes intending to reduce the length of the words until a minimum length is reached (for example economics, economia, economico to econom). After that, the Transform Cases operator was used to transform cases of characters to lower cases, and finally, to process documents, word vector was created using the Term Frequency method.

Figure 1. Process of text mining in RapidMiner Studio
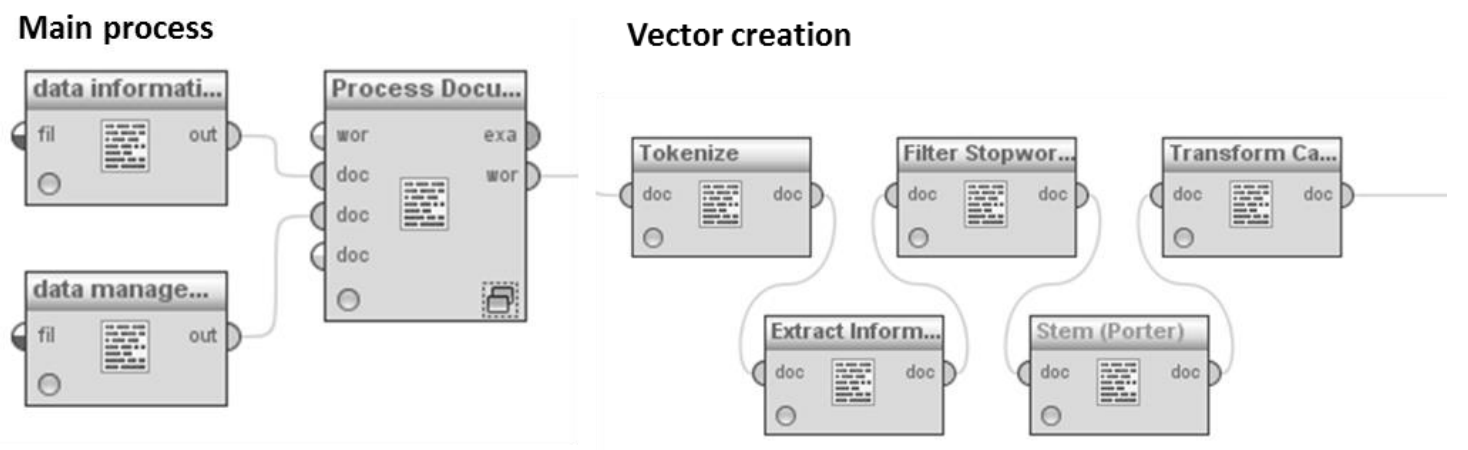

Source: Author

\section{RESULTS}

\section{The overall analysis of the smart city research}

Looking at the number of total publications from WoS (4.994) in the maximum searchable period from 1955 to 2020 , the growth of publications in smart city research in the last decade can be observed. Figure 2 shows the number of total publications for the last decade that has grown since 2010 from 2 papers published per year to over 900 papers in 2017, 2018, and 2019. The reasons for such rapid growth can be found in the marketing attractiveness of the term itself, which overlaps and historically replaces terms such as digital city, electronic city, information city, and similar on the one hand, and on the other, in the growing number of the application of modern ICT in cities. For example, in the period from 1990 to 1999, only 4 papers on smart city research were reported in the WoS database.

Figure 2. Number of publications in WoS database related to smart city research in the last decade

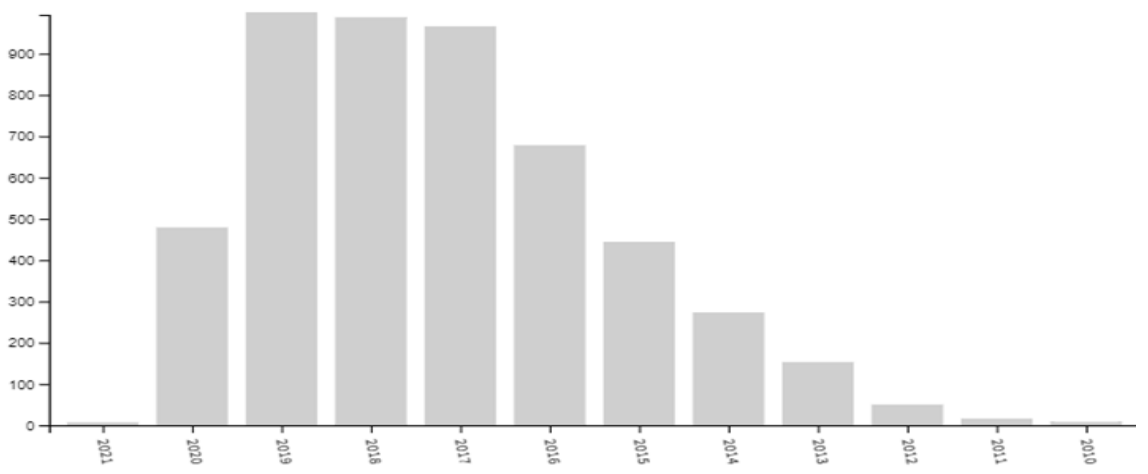

Source: Web of Science platform (https://apps.webofknowledge.com/) 
The sum of term frequency was calculated using RapidMiner as well, showing how frequently a word occurs in a document formed by a collection of abstracts from two specific databases (table 1 and table 2) and two perspectives. For readability in the tables below the number of terms shown is either top 10 or top 12 . The results of the text mining implemented in RapidMiner Studio for both perspectives (represented by document occurrences) within the smart city domain are presented in table 1 . In addition to the two most common terms "citi" and "smart", the terms "univ" (university), scienc" (science), "comput" (computing, computer...), "system", "data", and so on, have a high occurrence in the observed papers.

Table 1. Word occurrences in smart city research published in WoS database

\begin{tabular}{|c|l|c|c|}
\hline \multicolumn{1}{|c|}{ Attribute name } & Total occurrences & Document occurrences \\
\hline 1 & citi & 5.461 & 2 \\
\hline 2 & smart & 5.093 & 2 \\
\hline 3 & univ & 2.808 & 2 \\
\hline 4 & scienc & 2.521 & 2 \\
\hline 5 & comput & 2.440 & 2 \\
\hline 6 & system & 1.858 & 2 \\
\hline 7 & data & 1.634 & 2 \\
\hline 8 & manag & 1.578 & 2 \\
\hline 9 & inform & 1.465 & 2 \\
\hline 10 & ieee & 1.393 & 2 \\
\hline 11 & research & 1.393 & 2 \\
\hline 12 & technolog & 1.321 & \\
\hline
\end{tabular}

Source: Author

When analysing 7.099 papers published in the Scopus database on the topic, similar to in the WoS database, a sharp increase in the number of published papers from the smart city domain in the last decade can be noticed. In the period from 1990 to 1999, 3 papers, and from 2000 to 2009 , only 8 papers were published.

Figure 3. Number of publications in Scopus database related to smart city research in the last decade

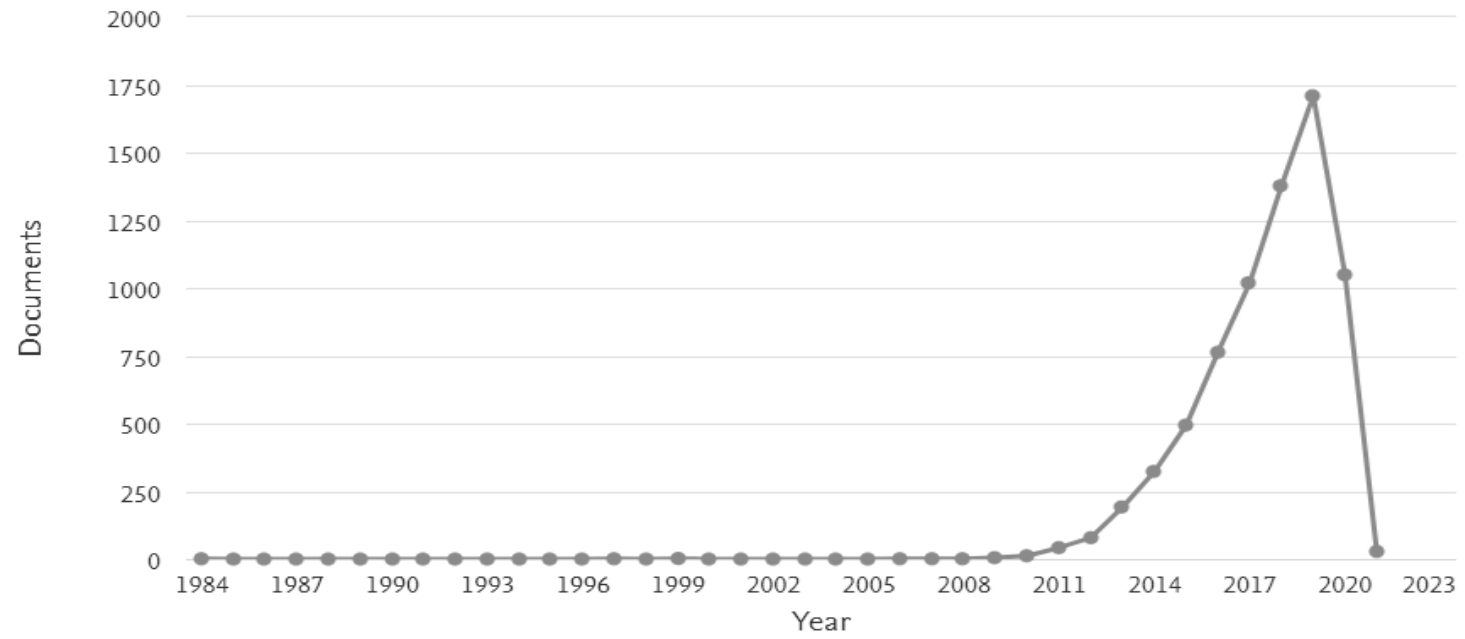

Source: Scopus platform (www.scopus.com)

The results of text mining conducted on abstracts of papers published in the Scopus database for both perspectives are presented in Table 2. In addition to the terms "citi" and "smart", the 
terms "data", "system", "technolog", "inform" and "manag" appear in the top 12 terms in papers represented in Scopus databases for both perspectives.

Table 2. Word occurrences in smart city research published in Scopus

\begin{tabular}{|c|l|c|c|}
\hline & Attribute name & Total occurrences & Document occurrences \\
\hline 1 & citi & 14.383 & 2 \\
\hline 2 & smart & 13.732 & 2 \\
\hline 3 & data & 5.402 & 2 \\
\hline 4 & system & 4.637 & 2 \\
\hline 5 & technolog & 3.313 & 2 \\
\hline 6 & network & 3.092 & 2 \\
\hline 7 & develop & 2.857 & 2 \\
\hline 8 & record & 2.731 & 2 \\
\hline 9 & servic & 2.658 & 2 \\
\hline 10 & urban & 2.621 & 2 \\
\hline 11 & inform & 2.468 & 2 \\
\hline 12 & manag & 2.356 & \\
\hline
\end{tabular}

Source: Author

Analysis of the common terms and differences between the two databases are presented below while considering the two different perspectives in more detail.

\section{Information systems perspective}

Looking at the WoS database from the information systems perspective in the smart city domain, a total of 1.038 records were analysed. The highest number of papers was authored in China (228), followed by the USA (158), Italy (106), England (80), and Spain (71) according to the geographical distribution of the literature on smart city information systems perspective. Word occurrences from this particular perspective in WoS are presented in Table 3.

Table 3. Information systems perspective - word occurrences in WoS database

\begin{tabular}{|c|l|c|c|c|}
\hline \multicolumn{1}{|c|}{$\begin{array}{c}\text { Attribute } \\
\text { name }\end{array}$} & $\begin{array}{c}\text { Total } \\
\text { occurrences }\end{array}$ & \% of represented occurrences & $\begin{array}{c}\text { \% of total } \\
(\mathbf{1 5 6 . 8 4 1})\end{array}$ \\
\hline 1 & citi & 2.762 & 15.07 & 1.76 \\
\hline 2 & smart & 2.695 & 14.70 & 1.72 \\
\hline 3 & comput & 2.341 & 12.77 & 1.49 \\
\hline 4 & scienc & 2.184 & 11.91 & 1.39 \\
\hline 5 & univ & 1.781 & 9.72 & 1.14 \\
\hline 6 & system & 1.577 & 8.60 & 1.01 \\
\hline 7 & ieee & 1.375 & 7.50 & 0.88 \\
\hline 8 & data & 1.311 & 7.15 & 0.84 \\
\hline 9 & inform & 1.225 & 6.68 & 0.78 \\
\hline 10 & network & 1.079 & 5.89 & 0.69 \\
\hline
\end{tabular}

Source: Author

In the Scopus database for information systems perspective, a total number of 4.631 records were found; however, only the first 2.000 records can be viewed from the database, so the analysis was made on a sample, i.e. a reduced number of papers. The highest number of papers was authored in the USA 599, followed by China 574, India 527, Italy 430, and Spain 329 
according to the geographical distribution of the literature on smart city information systems perspective. Word occurrences from this particular perspective in WoS are presented in Table 4.

Table 4. Information systems perspective - word occurrences in Scopus database (from 2.000

\begin{tabular}{|c|l|c|c|c|}
\hline & $\begin{array}{c}\text { Attribute } \\
\text { name }\end{array}$ & $\begin{array}{c}\text { Total } \\
\text { occurrences }\end{array}$ & \% of represented occurrences & $\begin{array}{c}\text { \% of total } \\
(\mathbf{3 2 4 . 4 4 3})\end{array}$ \\
\hline 1 & citi & 9.757 & 23.90 & 3.01 \\
\hline 2 & smart & 9.585 & 23.48 & 2.95 \\
\hline 3 & data & 4.531 & 11.10 & 1.40 \\
\hline 4 & system & 3.881 & 9.51 & 1.20 \\
\hline 5 & network & 2.742 & 6.72 & 0.85 \\
\hline 6 & technolog & 2.357 & 5.77 & 0.73 \\
\hline 7 & servic & 2.077 & 5.09 & 0.64 \\
\hline 8 & record & 2.068 & 5.07 & 0.64 \\
\hline 9 & inform & 1.956 & 4.79 & 0.60 \\
\hline 10 & internet & 1.870 & 4.58 & 0.58 \\
\hline
\end{tabular}

\section{Source: Author}

Looking at the information systems perspective in the smart city domain in the WoS and Scopus databases, it is possible to notice some common phenomena and differences. For example, in the top 10 terms, 6 terms: "citi", "smart", "system", "network", "data", and "inform" are common. Also, all key terms from both databases are related to the smart city domain and information system perspective.

\section{Management perspective}

From a management perspective in the smart city domain in the WoS database, 342 records were analysed. The highest number of papers was authored in Italy (51), the USA (43), England (32), China (32), and Russia (26) in terms of the geographical distribution of the literature on the smart city from the management perspective.

Table 5. Management perspective - word occurrences in WoS database

\begin{tabular}{|c|l|c|c|c|}
\hline \multicolumn{1}{|c|}{$\begin{array}{c}\text { Attribute } \\
\text { name }\end{array}$} & $\begin{array}{c}\text { Total } \\
\text { occurrences }\end{array}$ & \% of represented occurrences & $\begin{array}{c}\text { \% of total } \\
\mathbf{( 7 3 . 9 4 3 )}\end{array}$ \\
\hline 1 & citi & 2.699 & 24.18 & 3.38 \\
\hline 2 & smart & 2.398 & 21.48 & 3.00 \\
\hline 3 & univ & 1.027 & 9.20 & 1.28 \\
\hline 4 & manag & 1.014 & 9.08 & 1.27 \\
\hline 5 & busi & 940 & 8.42 & 1.18 \\
\hline 6 & econom & 715 & 6.40 & 0.89 \\
\hline 7 & develop & 664 & 5.95 & 0.83 \\
\hline 8 & urban & 609 & 5.46 & 0.76 \\
\hline 9 & technolog & 559 & 5.01 & 0.70 \\
\hline 10 & research & 539 & 4.83 & 0.67 \\
\hline
\end{tabular}

Source: Author 
In the Scopus database from the same perspective, there were 650 records. The highest number of papers was authored in the USA (82), followed by Italy (78), United Kingdom (57), India (56), and Spain (44) in terms of the geographical distribution.

Table 6. Management perspective - word occurrences in Scopus database

\begin{tabular}{|c|l|c|c|c|}
\hline & $\begin{array}{c}\text { Attribute } \\
\text { name }\end{array}$ & $\begin{array}{c}\text { Total } \\
\text { occurrences }\end{array}$ & \% of represented occurrences & $\begin{array}{c}\text { \% of total } \\
\mathbf{( 9 9 . 6 3 5 )}\end{array}$ \\
\hline 1 & citi & 4.626 & 30.62 & 4.64 \\
\hline 2 & smart & 4.147 & 27.45 & 4.16 \\
\hline 3 & develop & 991 & 6.56 & 0.99 \\
\hline 4 & technolog & 956 & 6.33 & 0.96 \\
\hline 5 & urban & 896 & 5.93 & 0.90 \\
\hline 6 & data & 871 & 5.77 & 0.87 \\
\hline 7 & system & 756 & 5.00 & 0.76 \\
\hline 8 & scopu & 654 & 4.33 & 0.66 \\
\hline 9 & manag & 630 & 4.17 & 0.63 \\
\hline 10 & servic & 581 & 3.85 & 0.58 \\
\hline
\end{tabular}

Source: Author

Management perspective in the smart city domain in WoS and Scopus databases also has some common occurrences in the top 10 terms such as "citi", "smart", "develop", "technolog", "urban" and "manag". Taking into account the results of common occurrences of terms for each of the perspectives within both databases, it can be concluded that papers categorised as falling within the information system perspective most often include terms related to system, network and inform (information, informatisation), while the papers within the management perspective most often include the terms develop, technologist, urban and manag (management, managerial and so on). If the perspectives are observed within each database separately, it is possible to come up with a somewhat more detailed description of each perspective. Thus, the perspectives information system and management in the WoS database had the common terms "citi", "smart" and "univ". The remaining terms that occur when looking at the information system perspective were "comput", "scienc", "system", "ieee", "data", "inform", and "network", and within the perspective management "manag", "busi", "economy", "develop", "urban", "technolog" and "research". In the Scopus database, the information system and management perspectives had some common terms such as: "citi", "smart", "technolog", "data", "system" and "service". The remaining terms that occur within the information system perspective were "network", "record", "inform" and "internet", and within the management perspective: "develop", "urban", "scopu" and "manag". The above text mining analysis of the occurrences of key terms within the two perspectives in the WoS and Scopus databases indicates that there are common terms that are investigated and studied within the smart city domain regardless of the perspective that the researchers take predominantly. On the other hand, there are also significant differences between the perspectives in papers within each database separately, but also between identical perspectives in different databases. The most obvious one is the term "network" in the information system perspective, this being a condition without which no smart city system would operate, and yet is secondary from the business side of the research. 


\section{Relating smart city categories with information system and management perspective}

To get more insight into the differences of the observed perspectives in the smart city domain, the occurrence of terms that make up six key categories of the smart city domain were analysed. The results of the occurrence of key terms (representing six key categories), according to the observed perspective and within the WoS and Scopus databases are shown in table 7.

Table 7. Smart city categories - word occurrences in WoS and Scopus databases

\begin{tabular}{|l|c|c|c|c|c|c|c|c|}
\hline \multirow{2}{*}{$\begin{array}{l}\text { Smart city } \\
\text { categories }\end{array}$} & \multicolumn{9}{|c|}{ WoS } & \multicolumn{5}{c|}{ Scopus } \\
\cline { 2 - 9 } & IS & \% & Mng & \% & IS & \% & Mng & \% \\
\hline govern & 188 & 0.12 & 350 & 0.44 & 819 & 0.25 & 541 & 0.54 \\
\hline peopl & 646 & 0.41 & 183 & 0.23 & 375 & 0.12 & 124 & 0.12 \\
\hline living & 0 & 0 & 0 & 0 & 0 & 0.00 & 0 & 0.00 \\
\hline mobil & 323 & 0.21 & & 0 & 1027 & 0.32 & 197 & 0.20 \\
\hline econom* & 90 & 0.06 & 902 & 1.13 & 470 & 0.14 & 336 & 0.34 \\
\hline environ** & 304 & 0.19 & 199 & 0.25 & 1217 & 0.38 & 343 & 0.34 \\
\hline Total & 156.841 & $/$ & 79.943 & 100 & 324.443 & $/$ & 99.635 & $/$ \\
\hline
\end{tabular}

IS = Information system perspective, Mng = Management perspective

Source: Author

Figure 4, similar to table 7, shows the relative occurrence of key terms according to the observed perspective and within the WoS and Scopus databases. However, data visualisation indicates more clearly a noteworthy difference when smart city categories from the information systems and management perspectives are observed.

Figure 4. Smart city categories from the information system and management perspectives

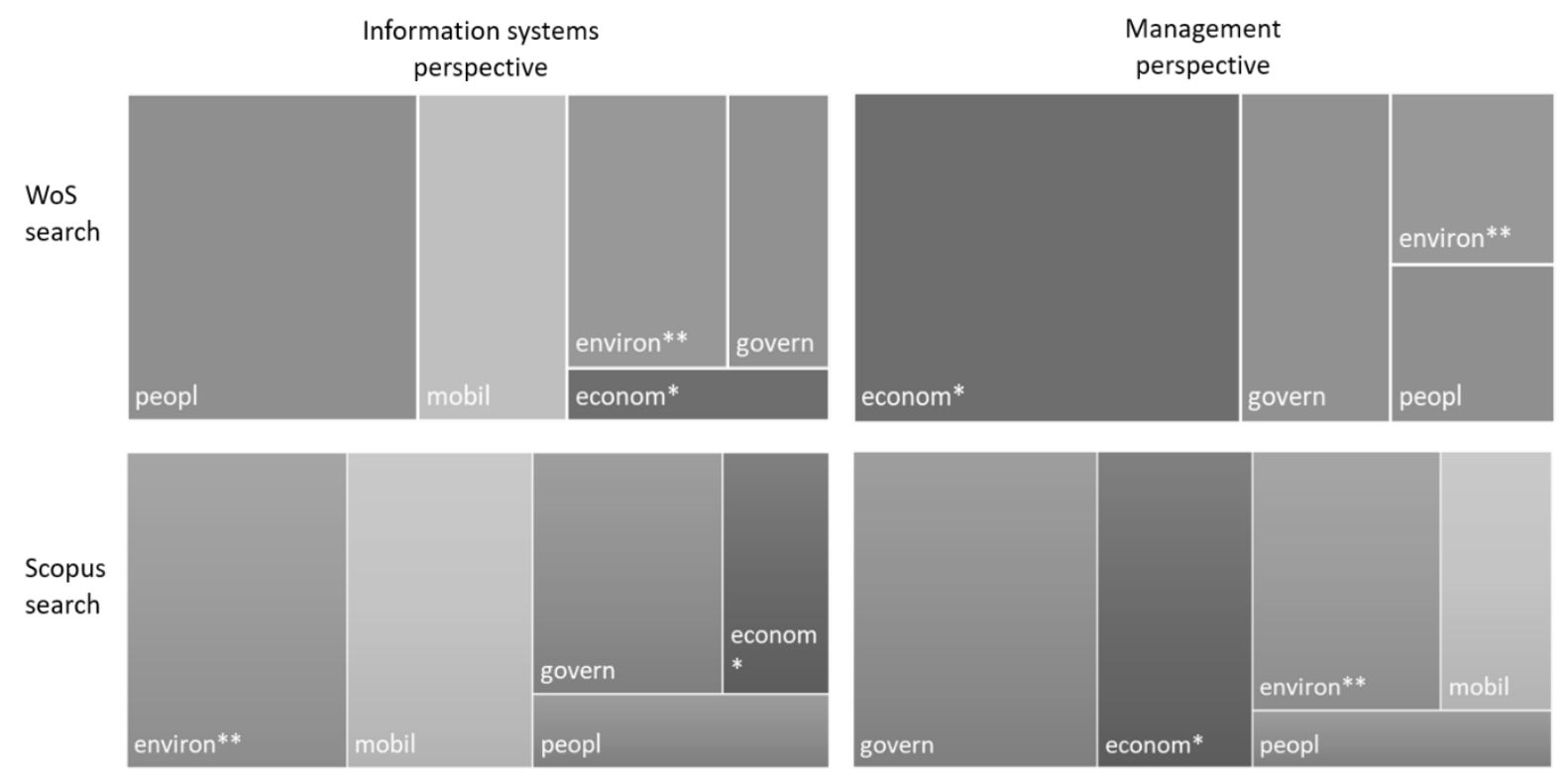

Source: Author

From the information system perspective, the terms "people" and "mobil" in the WoS database, and "environ **" and "mobil" in the Scopus database occur most often. Consequently, from the aspect of smart environment, smart mobility and smart people that stand out as most 
important for this perspective, it can be concluded that the convergence of big data, Internet of Things, and artificial intelligence promises to create cities as better, environment-friendly places to live in, by providing a more advanced infrastructure. Another key aspect of smart city research is the issue of mobility as the ultimate goal of many studies is to help improve the current state of congestion in urban areas. Conversely, from the management perspective, the terms "econom*" and "govern" in the WoS database, and "govern" and "econom*" in the Scopus database occur most often. This connects with research trends where recently smart governance, smart environment, smart mobility, and smart people are the basis for innovation in the business environment (in the smart economy) and everyday life (smart living). Furthermore, although the term "living" has not occurred in any of the variants (nor database or perspective), this category (smart living) is represented by studies that aim to improve health, education, and social services, as the remaining five key categories of smart cities positively impact all of these elements (Appio et al., 2018).

\section{Overview of highly cited papers from the information system and management perspectives in smart city research}

In the top ten cited WoS papers from the information systems perspective, the topic of IoT and mobility prevails in smart city research. In these papers, the Internet of Things (IoT) paradigm refers to "a network of interconnected things, i.e. devices with a telecommunications interface, processing, and storage units" (Centenaro, 2016), while the mobility studies mostly deal with traffic congestion, parking problems, and the upcoming advancement of smart vehicles and autonomous technologies (Aloqaily et al., 2019). It should be noted that some authors specifically address aspects of smart services and smart devices in cities. Smart services are an important element of smart cities and complementary to IoT where sensory data play the most significant role (Mohammadi et al., 2018). On the same note, other highly-cited papers, provide an overview of smart devices embedded in smart city infrastructures and a data-driven perspective (Hu et al., 2019), and also describe basic data management techniques used to ensure consistency, interoperability, granularity, and reuse of IoT-data generated for smart cities (Gharaibeh et al., 2017). Centenaro (2016) presented a new approach to connectivity in an IoT environment, discussing its advantages over established paradigms of applications in smart cities. Also, Rathore et al. (2016) propose a system for smart cities and urban planning that uses IoT-generated big data analysis. A complementary topic, smart mobility, has captured the attention of many authors. For example, the future of connected vehicles for smart cities is investigated, especially considering the availability of IoT devices (Aloqaily et al., 2019). To manage distributed and real-time traffic, Ning et al. (2019) propose the integration of fog computing and automotive networks. In their work, Teng et al. (2019) propose a model that uses vehicles to assist IoT applications in terms of data delivery. Another area is strongly impacted by IoT-related research and availability of IoT devices - smart energy; e.g. Liu et al. (2019) focus on designing an IoT-based energy management system that facilitates the integration of different energy sources and automatic control of the operation. Finally, Hossain et al. (2017) propose a smart healthcare monitoring framework that communicates with surrounding smart devices to enable affordable healthcare.

The ten most-cited WoS papers from a management perspective in smart city research are dominated by case study analyses that offer guidelines for smart city development, but also literature reviews and conceptual papers that generate new scientific insights into the field. Topics cover the area of smart governance, but also broadly cover the use of technologies in the areas of the economy, environment, people, mobility, and others. For example, Kumar et al. (2018) propose a smart city transformation framework to help policymakers, urban planners, 
and service providers in terms of understanding and better insight into smart solutions for smart city development. Mohamed et al. (2018) focus on technologies such as the IoT, robotics, and autonomous systems, and their integration into smart cities. Chang et al. (2018) define the relationship between IoT, smart cities, and hearing aids and present opportunities for their better development, all to raise the living standards of residents. As already noted, case studies fill the research gap by reporting on the results of multiple case studies conducted in European cities with examples of best practices (Mora et al., 2018). In this area, Caragliu and Del Bo (2018) contribute to the understanding of mechanisms to encourage urban innovation, while Appio et al. (2018) for better explaining the phenomenon of smart cities provide relevant links and thematic clusters in the domain of the smart city. Sepasgozar et al. (2018) develop a citizenoriented approach to smart cities by understanding the dimensions of technology acceptance, which plays a unique role in the acceptance of an increasing number of smart services by citizens. Similarly, Trencher (2018) aims to increase the understanding of how smart cities can be designed and implemented as a tool for solving social problems and addressing the needs of citizens. Another view of smart city development is increasingly based on knowledge management concepts. For example, Ardito et al. (2018) study the role of universities in the knowledge management of an increasing number of smart city projects, while Ferraris et al. (2017), had as their primary goal to examine how human resources are managed in smart city projects in multinational companies.

\section{LIMITATIONS AND FUTURE RESEARCH DIRECTIONS}

Although the paper aimed to eliminate the possible impact of varying paper lengths on the occurrence of key terms by using the abstracts exclusively, it is at the same time a limitation of the study. Specifically, the use of abstracts for text mining is an impairment since the abstracts are very short and represent only a sample of text/words presented in the whole paper. Thus, the subsequent phases would need to incorporate more extensive raw material, i.e. the entire paper, and compare the results. Also, the number of journals by research domain was not limited to get a broader picture and a full overview. Consequently, in future phases of the research, it would be interesting to verify whether the selection of journals specialising in the smart city domain affects the results presented in this paper significantly. Another limitation of the paper is the use of top $10 \mathrm{WoS}$ papers in each perspective to provide an overview of highly cited papers, given that this approach has a significant impact on the selection of highly cited journals as future outlets, for example, uncovering the journal "Technological Forecasting and Social Change" as a relevant one. In summation, and in addition to planned changes listed here, the future research agenda will include making a more extensive literature review by also incorporating papers from other databases.

\section{CONCLUSION}

As mentioned earlier, for this study, abstracts from almost 5.000 papers from the WoS database and more than 7.000 papers from the Scopus database were downloaded and analysed. Text mining procedure was performed on abstracts to uncover and interpret key terms and phenomena from the information systems and management perspectives in the smart city domain. The use of six key categories of smart cities as keywords within each perspective was also analysed and visualised.

There is a difference in terms of the geographical distribution of smart city research for observed perspectives. When looking at information systems perspective, the highest number of papers was authored in China followed by the USA and Italy and published in the WoS 
database, while in the Scopus database authors coming from the USA dominate, followed by authors from China and India. From the management perspective, the highest number of papers was published by authors from Italy, followed by the USA and UK in the WoS database, and in the Scopus database by authors from the USA, followed by Italy and UK. Also, there is a specific trend that can be recognised related to the time of publishing analysed papers, given that in both databases strong growth of published papers from the smart city domain starts in the last decade.

Papers on topics that address the issues of smart mobility, smart environment, and smart people dominate the information system perspective in smart city research. This is confirmed by a comprehensive analysis of the top 10 highly cited WoS papers, given that these papers mostly address the issue of smart mobility and various applications of IoT in the remaining key categories of smart cities, especially smart environment and people.

The management perspective is dominated by papers dealing with the smart economy and smart government. The results are also supported by an analytical overview of the top 10 highly cited WoS papers since these focus on smart governance but also broadly cover the use of technologies in the areas of the economy, environment, people, mobility, and so on.

In summation, and based on the common features but also the differences in smart city research, it can be said that information systems and management perspectives are equally represented and important. Thanks to information systems and hardware infrastructure, on the one hand, and management concepts, on the other hand, smart cities can equally develop all six key categories.

\section{ACKNOWLEDGMENT}

This research was supported by the Croatian Science Foundation [grant number UIP-201705-7625].

\section{REFERENCES}

Aloqaily, M., Otoum, S., Ridhawi, I. A., \& Jararweh, Y. (2019). An Intrusion Detection System for Connected Vehicles in Smart Cities. Ad Hoc Networks. doi:10.1016/j.adhoc.2019.02.001

Appio, F. P., Lima, M., \& Paroutis, S. (2018). Understanding Smart Cities: Innovation ecosystems, technological advancements, and societal challenges. Technological Forecasting and Social Change. doi:10.1016/j.techfore.2018.12.018

Ardito, L., Ferraris, A., Messeni Petruzzelli, A., Bresciani, S., \& Del Giudice, M. (2018). The role of universities in the knowledge management of smart city projects. Technological Forecasting and Social Change. doi:10.1016/j.techfore.2018.07.030

Caragliu, A., \& Del Bo, C. F. (2018). Smart innovative cities: The impact of Smart City policies on urban innovation. Technological Forecasting and Social Change. doi:10.1016/j.techfore.2018.07.022

Centenaro, M., Vangelista, L., Zanella, A., \& Zorzi, M. (2016). Long-range communications in unlicensed bands: the rising stars in the IoT and smart city scenarios, in IEEE Wireless Communications, vol. 23, no. 5, pp. 60-67, October 2016, DOI: 10.1109/MWC.2016.7721743. 
Chang, V., Wang, Y., \& Wills, G. (2018). Research investigations on the use or non-use of hearing aids in the smart cities. Technological Forecasting and Social Change. doi:10.1016/j.techfore.2018.03.002

Daenekindt, S., \& Huisman, J. (2020). Mapping the scattered field of research on higher education: a correlated topic model of 17,000 articles, 1991-2018. Higher education, 117. https://doi.org/10.1007/s10734-020-00500-x

Ferraris, A., Erhardt, N., \& Bresciani, S. (2017). Ambidextrous work in smart city project alliances: unpacking the role of human resource management systems. The International Journal of Human Resource Management, 1-22. doi:10.1080/09585192.2017.1291530

Gharaibeh, A., Salahuddin, M. A., Hussini, S. J., Khreishah, A., Khalil, I., Guizani, M., \& AlFuqaha, A. (2017). Smart Cities: A Survey on Data Management, Security, and Enabling Technologies. IEEE

Hossain, M. S., Muhammad, G., \& Alamri, A. (2017). Smart healthcare monitoring: a voice pathology detection paradigm for smart cities. Multimedia Systems. doi:10.1007/s00530017-0561-x

Hrcka, L., Simoncicova, V., Tadanai, O., Tanuska, P., Vazan, P. (2017). Using Text Mining Methods for Analysis of Production Data in Automotive Industry. Artif. Intell. Trends Intell. Syst. Adv. Intell. Syst. Comput.

Hu, L., Liu, A., Xie, M., \& Wang, T. (2019). UAVs joint vehicles as data mules for fast codes dissemination for edge networking in Smart City. Peer-to-Peer Networking and Applications. doi:10.1007/s12083-019-00752-0

Jadrić M., Mijač T., Ćukušić M. (2020) Text Mining the Variety of Trends in the Field of Simulation Modelling Research. In: Buchmann R.A., Polini A., Johansson B., Karagiannis D. (eds) Perspectives in Business Informatics Research. BIR 2020. Lecture Notes in Business Information Processing, vol 398. Springer, Cham. https://doi.org/10.1007/978-3-030-61140-8_10

Justicia De La Torre, C., Sánchez, D., Blanco, I., Martín-Bautista, M.J. (2018). Text mining: Techniques, applications, and challenges. Int. J. Unc., Fuzz. KB. Syst. 26(4), 553-582. https://doi.org/10.1142/S0218488518500265

Kaur, A., Chopra, D.; Comparison of Text Mining Tools. In 5th International Conference on Reliability, Infocom Technologies and Optimisation (ICRITO), 365-376, (2016).

Kumar, H., Singh, M. K., Gupta, M. P., \& Madaan, J. (2018). Moving towards smart cities: Solutions that lead to the Smart City Transformation Framework. Technological Forecasting and Social Change. doi:10.1016/j.techfore.2018.04.024

Liu, Y., Yang, C., Jiang, L., Xie, S., \& Zhang, Y. (2019). Intelligent Edge Computing for IoTBased Energy Management in Smart Cities. IEEE Network, 33(2), 111-117.

Manville C, et al. (2014). Mapping Smart Cities in the EU doi:10.1017/CBO9781107415324.004.

Mohamed, N., Al-Jaroodi, J., Jawhar, I., Idries, A., \& Mohammed, F. (2018). Unmanned aerial vehicles applications in future smart cities. Technological Forecasting and Social Change. doi:10.1016/j.techfore.2018.05.004

Mohammadi, M., Al-Fuqaha, A., Guizani, M., \& Oh, J.-S. (2018). Semisupervised Deep Reinforcement Learning in Support of IoT and Smart City Services. IEEE Internet of Things Journal, 5(2), 624-635. doi:10.1109/jiot.2017.2712560

Mora, L., Deakin, M., \& Reid, A. (2018). Strategic principles for smart city development: A multiple case study analysis of European best practices. Technological Forecasting and Social Change. doi:10.1016/j.techfore.2018.07.035

Ning, Z., Huang, J., \& Wang, X. (2019). Vehicular Fog Computing: Enabling Real-Time Traffic Management for Smart Cities. IEEE Wireless Communications, 26(1), 8793. doi:10.1109/mwc.2019.1700441 
North, M., (2012). Data Mining for the Masses, Global Text Project

RapidMiner: RapidMiner. 2020. [Online]. Available: http://docs.rapidminer.com/.

Rathore, M. M., Ahmad, A., Paul, A., \& Rho, S. (2016). Urban planning and building smart cities based on the Internet of Things using Big Data analytics. Computer Networks, 101, 63-80. doi:10.1016/j.comnet.2015.12.023

Sepasgozar, S. M. E., Hawken, S., Sargolzaei, S., \& Foroozanfa, M. (2018). Implementing citizen centric technology in developing smart cities: A model for predicting the acceptance of urban technologies. Technological Forecasting and Social Change. doi:10.1016/j.techfore.2018.09.012

Teng, H., Liu, W., Wang, T., Liu, A., Liu, X., \& Zhang, S. (2019). A Cost-Efficient Greedy Code Dissemination Scheme Through Vehicle to Sensing Devices (V2SD) Communication in Smart City.

Trencher, G. (2018). Towards the smart city 2.0: Empirical evidence of using smartness as a tool for tackling social challenges. Technological Forecasting and Social Change. doi:10.1016/j.techfore.2018.07.033 